\title{
Estimation and Analysis of Output Gap: An Application of Structural Vector Autoregression and Hodrick-Prescott-Fmethods
}

\author{
${ }^{1}$ Saeed Dehghan Khavari and ${ }^{2}$ Seyed Hossein Mirjalili \\ ${ }^{1}$ Department of Economics, Yazd University, Yazd, Iran \\ ${ }^{2}$ Institute for Humanities, Faculty of Economics, Tehran, Iran
}

\begin{abstract}
In this study we examined output gap in the Iranian economy. The main question of the study is that how much is seasonal output gap in Iranian Economy and which factor affects gap variation. The other question is that whether using HP-F as a statistical based method for estimating output gap, provide different result than using SVAR as theory based method. Accordingly the aim of study is to estimate potential output and thus output gap using two method and analysis of the result. We used two methods (Hodrick-Prescott Filter and SVAR) to estimate quarterly output gap for the period 1988:1-2008:4. The results pointed out that the estimation is not sensitive to the method and there is a close relation between oil revenue and output gap. In the period of 1998:3-1999:3, when oil price reduced to $\$ 11.45$ per barrel, Iranian economy faced with a recession and it affected on output gap with a lag. Output gap increased from 34818 in 2004:1-76782 million dollars in 2008: 4. The comparison of estimated output gap and changes of oil price in different periods point out the positive relation. According to the estimations of output gap, output gap in the Iranian Economy has intense fluctuation due to the effects of oil proceeds fluctuations. In some years, actual output is more than potential output, that is, output gap is positive and so this situation can be an important reason for inflation in that period and policy maker must do plans and policies for control of inflation and in some years, actual output is less than potential output and this means output gap was negative. This situation is a reason for unemployment in these years and therefore policy makers must do expansionary policies.
\end{abstract}

Keywords: Output Gap, Structural Var, Hodrick-Prescott Filter, Iran JEL: C13, C22, E1, E321, Iranian Economy, Expansionary Policies, Policy Makers, Intense Fluctuation

\section{INTRODUCTION}

The gap between actual and potential output is a key variable. While output in excess of potential, leads to higher inflation, sustained disinflation requires output to fall below potential.

If reliable, they would provide an important guide for policymakers in determining whether developments in the real economy are consistent with the maintenance of price stability. They could also assist policymakers in determining whether spending decisions and tax settings are consistent with the output gap. There are a number of Corresponding Author: Seyed Hossein Mirjalili, Institute for Humanities, Faculty of Economics, Iran reasons why central banks and governments and more generally the private sector, require accurate measures of the degree of spare capacity in the economy and the economy's long-term sustainable growth rate.

The Central Bank's need for economy-wide estimates of output gap reflects its statutory responsibility to maintain stability in the general level of prices. If the Central Bank mismeasures the level of output gap and calculates a positive output gap demand exceeds sustainable supply when in fact the gap is negative (sustainable supply exceeds demand), the consequent monetary policy tightening will tend instead 
to amplify the business cycle, offsetting some of the efficiency and allocative gains that a stable price environment may be expected to deliver. Similarly, if the Central Bank observes a rise in the rate of output growth, it needs to distinguish whether this is purely a positive demand shock and therefore possibly inflationary or simply the result of the economy responding to faster growth in the capacity of the economy to supply and therefore not inflationary. Likewise, if the Central Bank observes a fall in actual output growth, it needs to distinguish whether this is the result of a negative demand shock (and therefore possibly deflationary or a negative supply shock and therefore possibly inflationary. The concept of output gap is also important from the perspective of the Government. In the short term, an assessment of the degree of excess demand or excess capacity in the economy will influence the fiscal policy stance. As with monetary policy, an overexpansionary stance at a time when excess demand conditions are evident or an over-contractionary stance when the spare resources are plentiful will tend to amplify the business cycle. In the medium term, views regarding the economy's sustainable growth potential and thus tax base are also required to guide the formulation of the Government's fiscal strategy. This is particularly important where Government to conduct fiscal policy in a transparent and prudent manner and to achieve specific reductions in the net public debt to GDP ratio.

\subsection{Literature Review}

Willems (2010) estimated Output Gap and separated trend from cycle via Bayesian estimation of a New Keynesian model, augmented with an unobserved components model for output. The resulting estimate compared with popular proxies used in the literature. It turns out that the model-based approach may have important advantages for the conduct of monetary policy.

BJ (2003) estimated the Output Gap as an Indicator for the Pressure on Price Change. The output gap for 2001 was estimated as-3 to- $4 \%$, this wide output gap may be thought of as the fundamental backdrop to the continuing gradual decline in current prices.

Tommaso et al. (2002) estimated output gaps for Luxembourg. This study reviews several of the many alternative methods of estimating output gaps and applies six of these to annual data for Luxembourg. The sign of the output gap on the different measures seems to be systematically related, suggesting that the methods are at least measuring a related concept.
Chagny and Dopke (2001) examined Output Gap in the Euro-Zone and provided estimates of output gap in Euro Zone by using different methods including Structural VAR. the results show the methods imply different turning points and the estimated level of the output gap differs greatly.

Slevin (2001) xamined potential output and output gap in Ireland. This study estimates potential output using a number of statistical trend methods and a Cobb Douglas production function.

Cerra and Saxena (2000) examined Output Gaps with Alternative Methods including Structural VAR for Sweden. The paper reviews a number of different methods that can be used to estimate potential output and output gap. The estimates show that output gap was between-5.5 and $0.2 \%$ in period, from 1997-1998.

Gounder and Morling (2000) measured potential output in Fiji. The paper reviews four methods that can be used to estimate potential output and the output gap, including linear trends, Hodrick-Prescott (HP) filters, aggregate production functions and structural vector autoregressions. The results suggest that the output gap is measured very imprecisely in Fiji

Wedekind and Milinski (2000) estimated potential output for New Zealand by a structural VAR approach. A measure of potential output is obtained using a Structural Vector Autoregression (SVAR) methodology.

Gordon (1998) reviews five methods of estimating it for Australian GDP data, including linear time trends, Hodrick-Prescott (HP) filter trends, multivariate HP filter trends, unobservable components models and a production function model. Estimates of the gap vary with the method used and are sensitive to changes in model specification and sample period.

Israel et al. (1995) examined potential output by the structural vector autoregression in the Mexican economy. They find that world oil shocks have been an important source of both actual and potential output fluctuations over a sample period extending from 1965-1994.

\section{MATERIALS AND METHODS}

We examined output gap by two methods; Hodrick Prescott filter and SVAR. At first because Iran is oil exporting country, then we used non-oil GDP rather than GDP. For seasonal data since in quarterly data, there are seasonal fluctuations, we applied seasonal adjustment with ratio to moving average method in order to reform trend without seasonal fluctuations on data. Second we used a logarithmic transformation on quarterly GDP to obtain a more homogeneous variance of a series and avoid numerical instability. 
Khavari, S.D. and S.H. Mirjalili / American Journal of Economics and Business Administration 4 (3): 180-189, 2012

Table 1. Unit Root Test on quarterly LGDP and first difference of it on the basis of augmented dicky -fuller and phillips perron tests

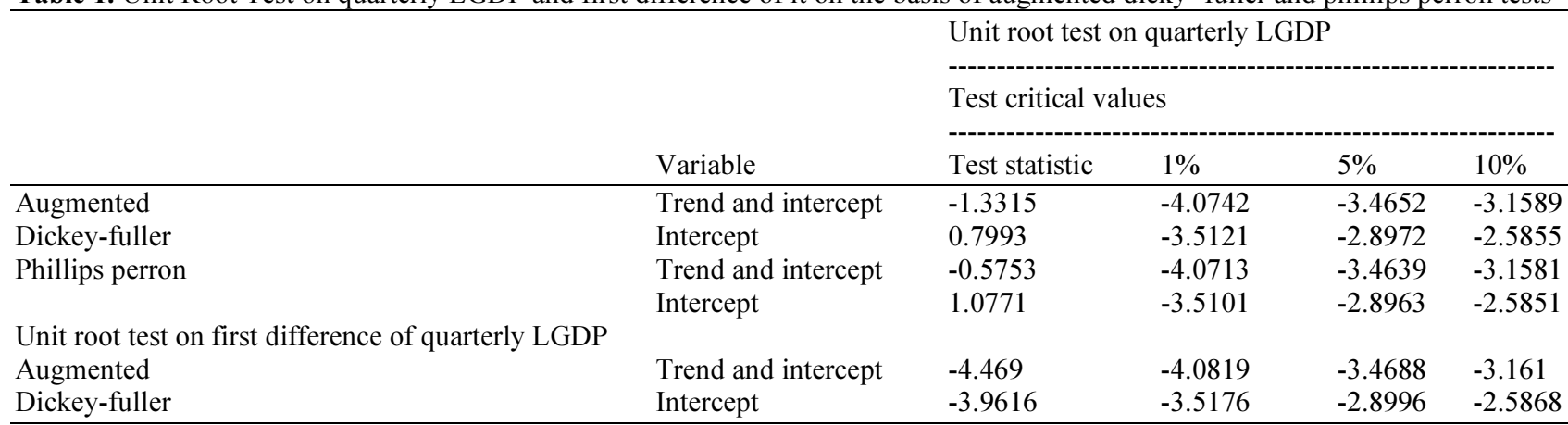

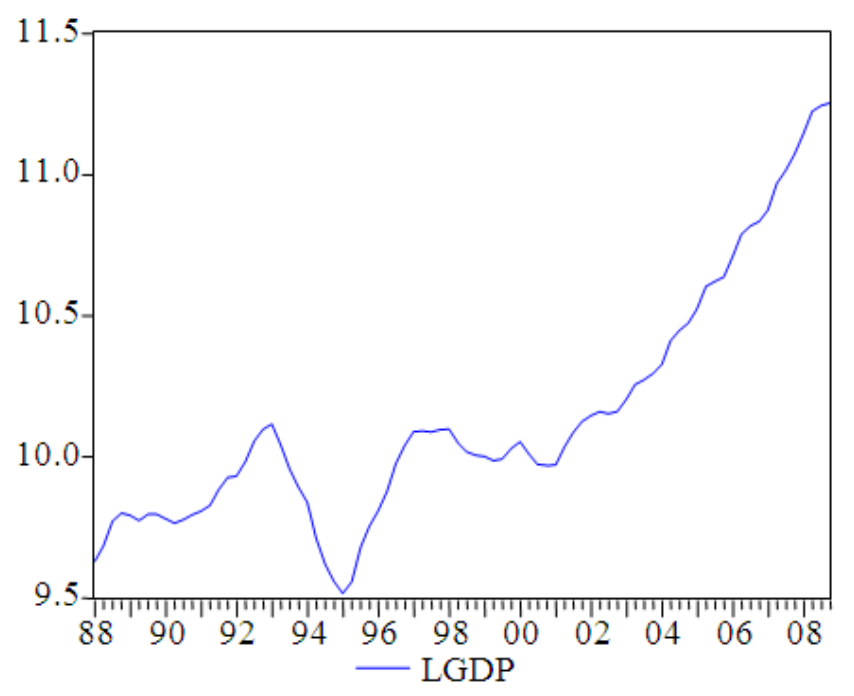

Fig. 1. Quarterly LGDP Trend (million Dollars)

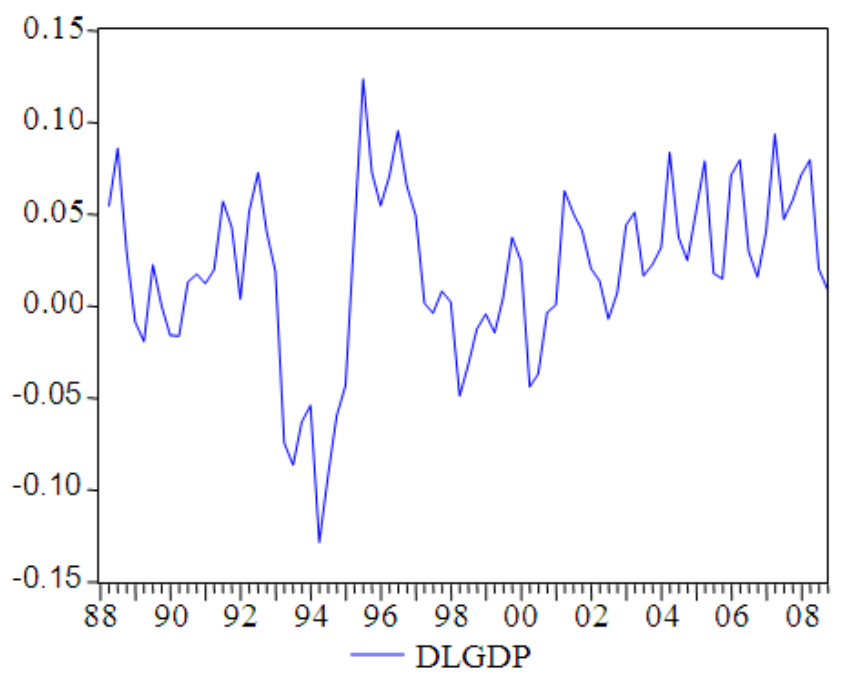

Fig. 2. First difference of quarterly LGDP Trend 
Third, we used unit root test on the logarithm of GDP (quarterly GDP data) in order to resolve spurious regression and other problems with non stationary time series.

\subsection{Unit Root Test}

For unit root tests, we applied Augmented DickyFuller Test and Phillips Perron Test. The results show that logarithm of gross potential output is not stationary in level.

Table 1 shows the results of the augmented DickeyFuller and Phillips and Perron tests of the null hypothesis of non stationary GDP. The results are unambiguous and clearly support the hypothesis that the time series are stationary in first differences.

The results of Augmented Dickey-fuller test on quarterly LGDP illustrated in Table 1. In this case, the test statistic is in critical values whether there is a constant and/or trend included. Therefore, we conclude that quarterly LGDP is non stationary. Appropriate lag length of dependent variable can be obtained from Akaike Information (AIC), Schwartz-Baysian (SBC) and Hannan-Quinn (HQC) Criteria.

Results of Phillips Perron Unit Root Test on LGDP and critical values in different significant levels have summarized in the table. This result is similar to Augmented Dickey Fuller test results. LGDP is not stationary on its level. On the basis of Phillips Perron Unit Root Test, Null Hypothesis of LGDP has a Unit Root doesn't reject. In other words LGDP has unit root and its fluctuations around time trend is not stationary.

Therefore we try on difference of LGDP for gain of a stationary time series. After testing by unit root tests we fine that LGDP is I (1). This means that D (LGDP)first difference of LGDP-is stationary. Augmented Dickey-fuller test on first difference of quarterly LGDP illustrated in Table 1. The test statistic is more than critical values whether there is a constant and/or trend included. Therefore DLGDP is stationary.

We can also find that LGDP is not stationary on level graphically. A visual plot of the data is usually the first step in the analysis of any time series. Any time series data can be thought of as being generated by a stochastic or random process and a concrete set of data, such as that shown in Fig. 1 can be regarded as non stationary because these time series visually, at least, their mean, variance and auto covariance do not seem to be time-invariant.

The first impression that we get from the time series plotted in the following figure is that it all seems to be trending upward, although the trend is not smooth. The Quarterly GDP is in fact non stationary time series.
Figure 2 shows First-Differenced Quarterly GDP in Iran. Compared with the GDP series (Quarterly Data) given in Fig. 1, the differenced GDP series shown in Fig. 2 does not show any trend. Therefore D (LGDP) in stationary. Because of D(LGDP) is stationary, as noted, it is an $\mathrm{I}(0)$ stochastic process, which means GDP itself is an I(1) time series and essentially it is a random walk.

\subsection{Hodrick-Prescott Filter}

The Hodrick-Prescott filter was created with the assumption that unobserved shocks to trend output occur all the time. The HP filter is a technique to distinguish output's long-term trend from its short-term business cycle variation. Applied economists adapted the filter by identifying the long-term trend as potential output.

The Hodrick-Prescott filter, is based on the assumption that a given time series yt is the sum of a trend or growth component gt and a cyclical componentct Equation (1):

$\mathrm{y}_{\mathrm{t}}=\mathrm{g}_{\mathrm{t}}+\mathrm{c}_{\mathrm{t}}$ For $\mathrm{t}=1, \ldots, \mathrm{T}$

According to Hodrick and Prescott (1997), "our prior knowledge is that the growth component varies 'smoothly' over time," where the measure of smoothness of the $\left\{g_{t}\right\}$ path is chosen to be the sum of the squares of its second difference. The cyclical component $c_{t}$ represents deviations from $g_{t}$ and over long time periods their average is assumed to be near zero. The growth component $g_{t}$ is extracted by minimizing the following loss function Equation (2):

$\operatorname{Min}\left\{\sum_{t=1}^{T} C^{2}{ }_{T} \lambda \sum_{t=1}^{T} C^{2}{ }_{T}\left[\left(g_{t}-g_{t-1}\right)-\left(g_{t-1} g_{t-2}\right)\right]^{2}\right\}$

The first sum represents the penalty for deviations of the observed series from the trend growth series $c_{t}=y_{t^{-}}$ $\mathrm{g}_{\mathrm{t}}$, while the second sum represents the penalty for sharp changes in the trend growth component.

We can define the filter as follows. If y denotes real GDP, the filter is defined as Equation (3):

$\min \sum_{\mathrm{t}=1}^{\mathrm{T}}\left(\mathrm{y}_{\mathrm{t}}-\mathrm{y}_{\mathrm{t}}^{*}\right)^{2}+\lambda \sum_{\mathrm{t}=2}^{\mathrm{T}-1}\left[\left[\left(\mathrm{y}_{\mathrm{t}}^{*}-\mathrm{y}_{\mathrm{t}}^{*}\right)-\left(\mathrm{y}_{\mathrm{t}}-\mathrm{y}_{\mathrm{t}-1}^{*}\right)\right]^{2}\right.$

With $\mathrm{y}^{*}$ as the smooth component which gives the estimate of potential GDP in this context. Broadly speaking the procedure contains two commands: (i) minimize the distance between the actual and the trend value of the time series and (ii) minimize the change of the trend value (Bhundia and Arora, 2003). 


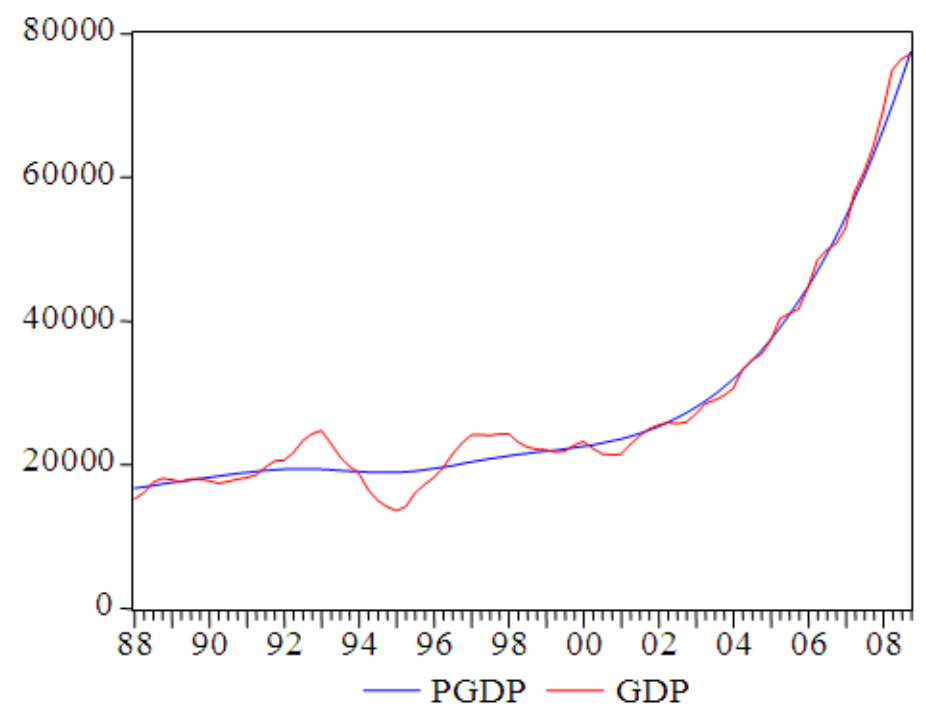

Fig. 3. Quarterly estimated potential output by Hodrick Prescott filter

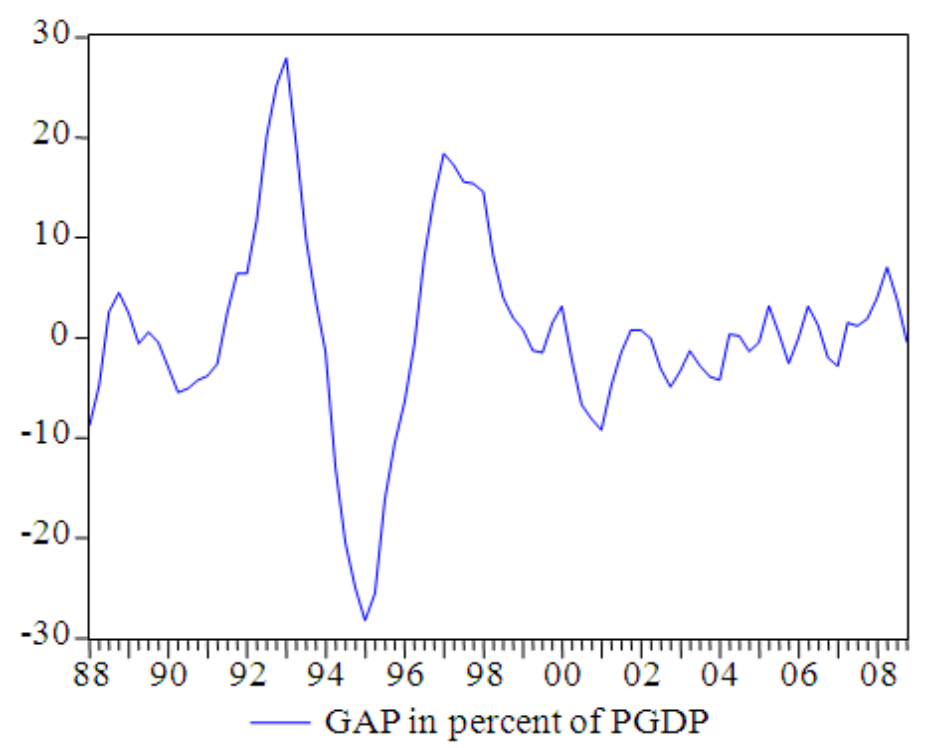

Fig. 4. Quarterly estimated output gap in percent of potential output by

Two arguments commonly made in favor of HP filter are that it extracts the relevant business-cycle frequencies of the spectrum and that it closely approximates the cyclical component implied by reasonable time series models of output (Burnside, 1998).

The filter involves the smoothing parameter $\lambda$ which penalizes the acceleration in the trend component relative to the business cycle component. Researchers typically set $\lambda=1600$ when working with quarterly data.
Most studies use the standard value of 1600 for the smoothing parameter involved in the HP-filter at the quarterly frequency as Hodrick and Prescott (1997) favored the choice of $\lambda=1600$ (Ravn and Uhlig, 1997).

Therefore as we used quarterly data, the smoothing parameter should be 1600 .

Figure 3 and 4 show potential output and output gap using Hodrick Prescott Filtering Methodology respectively. 


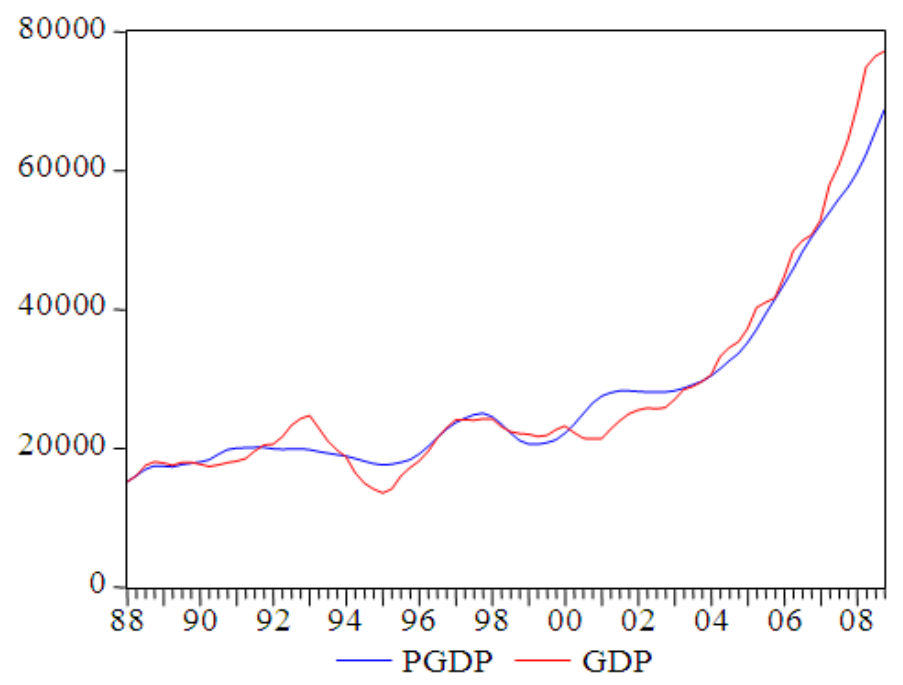

Fig. 5. Quarterly estimated potential output by SVAR

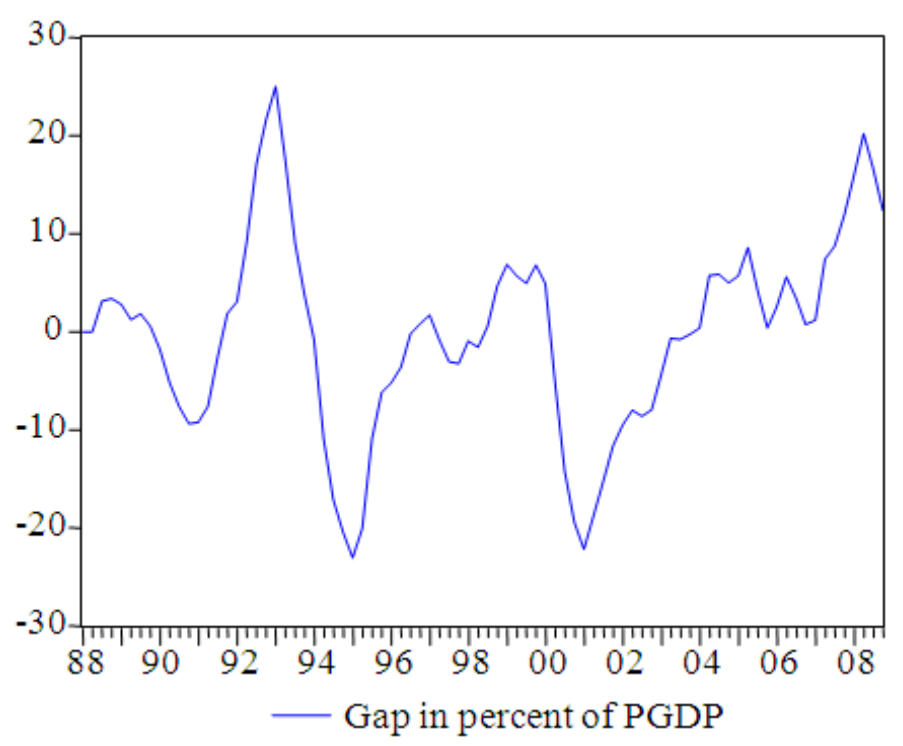

Fig. 6. Estimated Output gap in percent of potential output by SVAR method

\subsection{SVAR Method}

Structural vector autoregressive is a statistical approach which estimates a vector of variables, including the change in inflation and output, as a function of those same variables.

All variables are treated as endogenous and written as a linear combination of lagged values of itself and of the other variables in the system.

Mechanical filters, such as the Hodrick and Prescott (1997) filter, is technique that extract a trend measure from actual output series. However, these filters as we said in previous section have been criticized such as the HP filter with (nearly) integrated data can induce spurious cyclicality and also the HP filters do not accurately decompose time series into their trend and cyclical components when the data have the typical spectral Granger shape. The typical Granger shape is characteristic of nearly all macroeconomic time series. Moreover, this filter shows instability of estimates near the end of the sample period. 
Therefore we say SVAR advantages by following cases: First, Univariate and multivariate filters often assume that the trend component in output can be characterized as a random walk, an assumption that is not maintained in the SVAR approach.

Second, unlike some methods (such as trend-based methods, filter-based methods and the Beveridge-Nelson decomposition) the SVAR approach can be given an economic interpretation. For example, we can interpret fluctuations in potential output as being caused by certain types of shocks (Demand and supply shocks) whereas the other methods cannot. Third, contrary to other methods, such as those based on the HodrickPrescott filter, the VAR method does not require the imposition of an arbitrary smoothing parameter. Fourth, it theoretically overcomes the "end point problem" inherent in two sided filters (Blanchard and Quah, 1989; King et al., 1991).

We examine output gap through an approach derived from the structural vector autoregression (SVAR) methodology developed by Shapiro and Watson (1988); Blanchard and Quah (1989) and King et al. (1991). This methodology involves the estimation of a Vector Autoregression (VAR) model for the particular economy under study. We then identify different variables by making long-term assumptions based on macroeconomic theory. In order to distinguish among various sources of output fluctuation, we apply a variant of the structural VAR methodology to an autoregressive system composed of five variables, each follow a stationary stochastic process. It is assumed that the private consumption, the rate of growth of output, the monetary aggregate are endogenous and the price of oil and a dummy variable as defined in phase trend method are exogenous to the Iranian economy in the long term.

While unit-root tests suggest that the model variables are nonstationary in levels, it is still possible that a stationary linear combination of the variables could be found. In such a case, a vector error-correction model would have to be estimated, since estimating a VAR in first differences would remove important information about the behaviour of the variables that is contained in the common trend. We used the method proposed by Johansen (1988) and applied by Johansen and Juselius (1990) to test for cointegration between the four variables. The results of the tests support the hypothesis that there is cointegrating relationship between the variables considered in this study. Note that we also applied the single-equation procedure suggested by Engle and Granger (1987) and find evidence of cointegration using that approach either. Therefore the tests reject the null hypothesis of no cointegration. Consequently, we assume that the series in the model are cointegrated and that it is appropriate to estimate the VAR models in levels (of the logarithms). We estimated Multivariate VAR model with three endogenous variables and two exogenous ones. Figure 5 and 6 illustrate potential output and output gap using SVAR Method respectively.

\section{RESULTS}

In Table 2 numerical results of potential output illustrated by two methods.

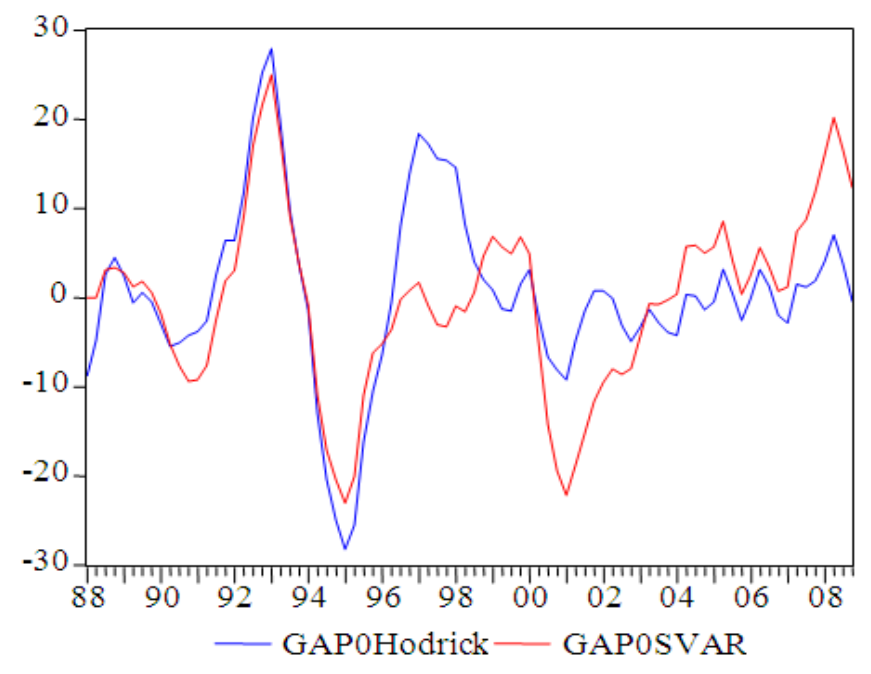

Fig. 7. Quarterly estimated output gap in percent of potential output by two methods 
Khavari, S.D. and S.H. Mirjalili / American Journal of Economics and Business Administration 4 (3): 180-189, 2012

Table 2. Quarterly numerical results of estimated potential output (million dollars)

\begin{tabular}{|c|c|c|c|c|c|c|c|}
\hline Range & GDP* & HP & SVAR & Range & GDP* & HP & SVAR \\
\hline 1988:01:00 & 15233 & 16696 & - & 1999:01:00 & 22058 & 21869 & 20646 \\
\hline 1988:02:00 & 16088 & 16893 & - & 1999:02:00 & 21743 & 22024 & 20573 \\
\hline 1988:03:00 & 17533 & 17092 & 17006 & 1999:03:00 & 21853 & 22185 & 20831 \\
\hline 1988:04:00 & 18065 & 17290 & 17475 & 1999:04:00 & 22691 & 22357 & 21250 \\
\hline 1989:01:00 & 17912 & 17487 & 17427 & 2000:01:00 & 23256 & 22546 & 22170 \\
\hline 1989:02:00 & 17573 & 17681 & 17366 & 2000:02:00 & 22262 & 22756 & 23453 \\
\hline 1989:03:00 & 17975 & 17872 & 17653 & 2000:03:00 & 21458 & 22995 & 25017 \\
\hline 1989:04:00 & 17977 & 18060 & 17874 & 2000:04:00 & 21385 & 23268 & 26537 \\
\hline 1990:01:00 & 17697 & 18243 & 18024 & 2001:01:00 & 21404 & 23580 & 27511 \\
\hline 1990:02:00 & 17414 & 18420 & 18377 & 2001:02:00 & 22792 & 23937 & 28046 \\
\hline 1990:03:00 & 17647 & 18592 & 19114 & 2001:03:00 & 23977 & 24342 & 28285 \\
\hline 1990:04:00 & 17959 & 18755 & 19818 & 2001:04:00 & 24982 & 24798 & 28280 \\
\hline 1991:01:00 & 18184 & 18907 & 20036 & 2002:01:00 & 25504 & 25309 & 28189 \\
\hline 1991:02:00 & 18547 & 19046 & 20079 & 2002:02:00 & 25861 & 25878 & 28107 \\
\hline 1991:03:00 & 19639 & 19167 & 20155 & 2002:03:00 & 25682 & 26511 & 28101 \\
\hline 1991:04:00 & 20499 & 19266 & 20123 & 2002:04:00 & 25873 & 27212 & 28115 \\
\hline 1992:01:00 & 20578 & 19341 & 19967 & 2003:01:00 & 27046 & 27986 & 28307 \\
\hline 1992:02:00 & 21672 & 19388 & 19868 & 2003:02:00 & 28465 & 28839 & 28666 \\
\hline 1992:03:00 & 23308 & 19405 & 19916 & 2003:03:00 & 28943 & 29775 & 29175 \\
\hline 1992:04:00 & 24277 & 19391 & 19970 & 2003:04:00 & 29604 & 30799 & 29684 \\
\hline 1993:01:00 & 24748 & 19348 & 19798 & 2004:01:00 & 30568 & 31917 & 30455 \\
\hline 1993:02:00 & 22975 & 19282 & 19552 & 2004:02:00 & 33241 & 33133 & 31441 \\
\hline 1993:03:00 & 21074 & 19199 & 19318 & 2004:03:00 & 34513 & 34452 & 32608 \\
\hline 1993:04:00 & 19787 & 19109 & 19087 & 2004:04:00 & 35383 & 35878 & 33702 \\
\hline 1994:01:00 & 18750 & 19023 & 18907 & 2005:01:00 & 37236 & 37415 & 35227 \\
\hline 1994:02:00 & 16491 & 18951 & 18519 & 2005:02:00 & 40306 & 39070 & 37130 \\
\hline 1994:03:00 & 15046 & 18905 & 18155 & 2005:03:00 & 41033 & 40847 & 39376 \\
\hline 1994:04:00 & 14177 & 18892 & 17822 & 2005:04:00 & 41651 & 42750 & 41495 \\
\hline 1995:01:00 & 13579 & 18919 & 17648 & 2006:01:00 & 44727 & 44787 & 43638 \\
\hline 1995:02:00 & 14147 & 18990 & 17699 & 2006:02:00 & 48438 & 46962 & 45872 \\
\hline 1995:03:00 & 16010 & 19104 & 17982 & 2006:03:00 & 49916 & 49281 & 48267 \\
\hline 1995:04:00 & 17224 & 19256 & 18361 & 2006:04:00 & 50719 & 51750 & 50359 \\
\hline 1996:01:00 & 18192 & 19442 & 19188 & 2007:01:00 & 52822 & 54373 & 52210 \\
\hline 1996:02:00 & 19532 & 19654 & 20268 & 2007:02:00 & 58011 & 57159 & 54016 \\
\hline 1996:03:00 & 21491 & 19883 & 21534 & 2007:03:00 & 60818 & 60109 & 55934 \\
\hline 1996:04:00 & 22946 & 20121 & 22762 & 2007:04:00 & 64414 & 63228 & 57574 \\
\hline 1997:01:00 & 24105 & 20360 & 23703 & 2008:01:00 & 69181 & 66521 & 59679 \\
\hline 1997:02:00 & 24147 & 20593 & 24353 & 2008:02:00 & 74912 & 69991 & 62332 \\
\hline 1997:03:00 & 24058 & 20815 & 24815 & 2008:03:00 & 76451 & 73644 & 65581 \\
\hline 1997:04:00 & 24255 & 21022 & 25074 & 2008:04:00 & 77178 & 77486 & 68693 \\
\hline 1998:01:00 & 24310 & 21215 & 24545 & & & & \\
\hline 1998:02:00 & 23152 & 21392 & 23526 & & & & \\
\hline 1998:03:00 & 22424 & 21558 & 22300 & & & & \\
\hline 1998:04:00 & 22150 & 21715 & 21163 & & & & \\
\hline
\end{tabular}

${ }^{*}$ Non-oil GDP after seasonal adjustment with ratio to moving average method

In Fig. 7 it was shown the results of estimated output gap.

The two measures of output gap were estimated for Iran. The results are shown in Fig. 7 and Table 2. Looking at Fig. 7, the graph shows that each method almost produces a similar result for output gap. The results pointed out that the estimation is not sensitive to the method.

\section{DISCUSSION}

Although results are almost near together but we have to select one method for analysis. Therefore we analyze the obtained results in economic viewpoint now by SVAR method for quarterly data because of SVAR method having the highest magnitude as we explained in previous sections. 


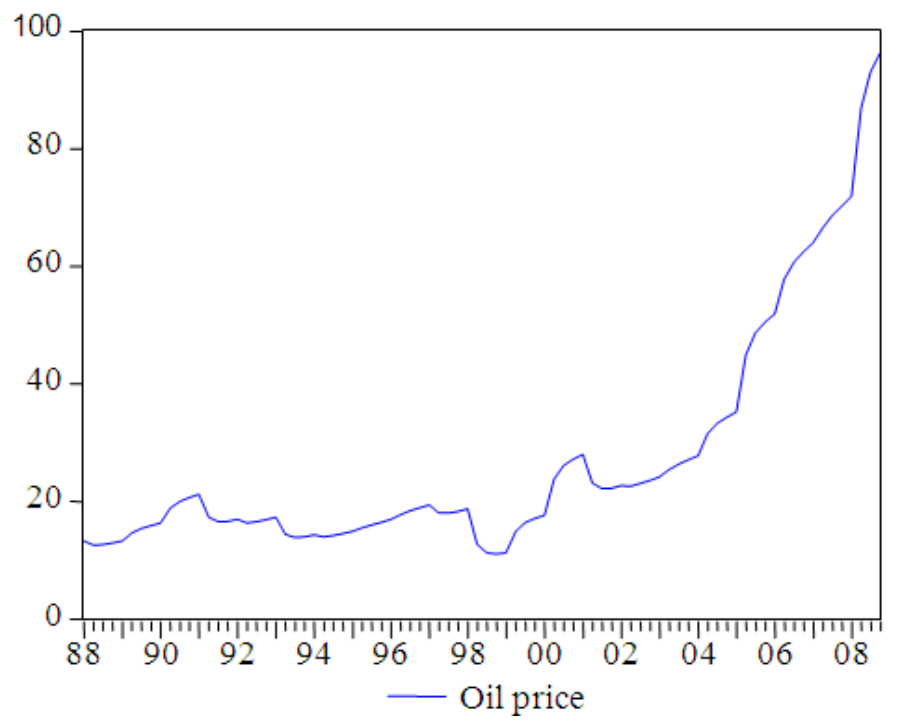

Fig. 8. Crude oil price per barrel(dollars)

The mean of output gap is- $0.09 \%$ with $27 \%$ maximum and-23\% minimum levels so that indicating severe fluctuations of output gap in Iranian economy in the period as depicted graphically.

This means that estimated output gap from this method fluctuates about between 27 and- 23 in percent of potential output. The highest and lowest levels are related to 1993:1 and 1995:1 respectively. The nearness of the maximum and minimum of output gap (1993:1 and 1995:1) shows instability and inconstancy in output gap level in Iranian economy. Therefore the question rise for what reason the fluctuation happened?

The plausible reason is that Iranian economy has relying upon oil income strongly, thus we measure correlation of two variables, e.g., potential output and oil income. Results show strong correlation between these variables (about 97\%) also this problem is applicable about potential output and liquidity so that correlation is about $98 \%$. The high correlation indicates tightly relation between oil income and potential output.

Correlation does not necessarily imply causation in any meaningful sense of that word. While there are high positive correlation between two variables but we need to examine the causality. Therefore we test Granger Causality Test for finding of causality and its direction.

The casualityapproach to the question of whether potential output causes oil income or the latter one causes the former. According to the results, we cannot reject the hypothesis that potential output does not Granger cause oil income but we do reject the hypothesis that oil income does not Granger cause potential output.
In other words oil income Granger causes potential output and then we can state a part of potential output is the effect or the result of oil income. Therefore it appears that Granger causality runs one-way from oil income to potential output and not the other way. Consequently oil income influences on potential output in Iranian economy.

The conclusion helps us better and more precise analysis of potential output changes. As it has shown in Fig. 8 in period 1988:1-1991:3 the oil price increased (from 12.85 \$ in 1988:1-19.91 \$ per barrel in 1990:4 for heavy oil) and therefore potential output increased from 20296 in 1988:3-24044 million dollars in 1991:3. Although increasing of oil price and potential output are not coordinated completely because of increasing oil price effect in economy with delay naturally.

In period of 1998:3-1999:3, there was a recession because of reducing oil price as it reduced to $11.45 \$$ a barrel. Iranian economy has been faced with a severe recession and it affects on output gap with delay. Reducing of oil price is an unfavorable shock because it affects on GDP, national income and ultimately output gap negatively. It is important that oil shocks have two effects on economy, favorable and unfavorable effect. In Iran economy, favorable oil shocks like the OPEC oil price increases of the 2000 s raise potential output in the long run. The oil price decreases which occurred in late 1990s were unfavorable oil shocks.

This process repeats more or less all of the period especially at the end of it, whereas potential output 
increased from 34818 in 2004:1-76782 million dollars in 2008:4. In other words it faces to increasing $120 \%$ from beginning to ending of period and $4.25 \%$ rate of growth seasonally whereas the oil price has increased from 33.06-91.49 dollars a barrel.

From an economic viewpoint, the effect of oil price on output gap point out that oil proceed has fundamental role in the economy so that the long run effect is a possible rising in the level of potential GDP or potential output. Thus, the long-run aggregate supply curve line may shift to the right in response to a supply shock. We see this issue in Fig. 5 and 6 so that oil shock in 2004-2008 causes increasing potential output and its trend is uprising.

\section{CONCLUSION}

According to the estimations of output gap, output gap in the Iranian Economy has intense fluctuation due to the effects of oil proceeds fluctuations. Therefore there are close relationship between oil proceeds and output gap in the Iranian Economy. In some years, actual output is more than potential output, that is, output gap is positive and so this situation can be an important reason for inflation in that period and policy maker must do plans and policies for control of inflation and in some years, actual output is less than potential output and this means output gap was negative. This situation is a reason for unemployment in these years and therefore policy makers must do expansionary policies. The comparison of estimated output gap and changes of oil price in different periods point out the positive relation. The estimation is also insensitive to the method of estimation and provides almost identical results.

We suggest potential output and therefore output gap are estimated every season. Policy makers must have more attention to potential output level and output gap. It can help to perform better economic five years plans. This can help to reduce unemployment and inflation.

\section{REFERENCES}

Bhundia, A. and V.B. Arora, 2003. Potential Output and Total Factor Productivity Growth in Post-Apartheid South Africa (EPub). 1st Edn., International Monetary Fund, ISBN-10: 1452700745, pp: 20.

$\mathrm{BJ}, 2003$. The role of the money stock in conducting monetary policy. Bank of Japan.

Blanchard, O. and D. Quah, 1989. The dynamic effects of aggregate demand and supply disturbances. Am. Econ. Rev., 79: 655-673.
Burnside, S.D., 1998. Self-organization of $\mathrm{tio}_{2}$ nanoparticles in thin films. Chem. Mater., 10: 24192425. DOI: $10.1021 / \mathrm{cm} 980702 \mathrm{~b}$

Cerra, V. and S.C. Saxena, 2000. What Caused the 1991 Currency Crisis in India. 1st Edn., International Monetary Fund, pp: 26.

Chagny, O. and J. Dopke, 2001. Measures of the output gap in the euro-zone: An empirical assessment of selected methods. Kiel Institute of World Economics.

Engle, R.F. and C.W.J. Granger, 1987. Co-Integration and Error Correction: Representation, estimation and testing. Econometrica, 55: 251-276.

Gordon, S., 1998. The role of the macrophage in immune regulation. Res. Immunol., 149: 685-688. DOI: 10.1016/S0923-2494(99)80039-X

Gounder, K. and S. Morling, 2000. Measures of Potential Output in Fiji. 1st Edn., Economics Department, Reserve Bank of Fiji, pp: 17.

Hodrick, R.J. and E.C. Prescott, 1997. Postwar U.S. business cycles: An empirical investigation. J. Money Credit Bank., 29: 1-16.

Israel, A., S. Jarriault, C. Brou, F. Logeat and E.H. Schroeter et al., 1995. Signalling downstream of activated mammalian Notch. Nature, 377: 355-358. DOI: $10.1038 / 377355 \mathrm{a} 0$

Johansen, S. and K. Juselius, 1990. Maximum likelihood estimation and inference on cointegration-with applications to the demand for money. Oxford Bull. Econ. Stat., 52 169-210. DOI: 10.1111/j.14680084.1990.mp52002003.x

Johansen, S., 1988. Statistical analysis of cointegration vectors. J. Econ. Dynam. Control, 12: 231-254. DOI: $10.1016 / 0165-1889(88) 90041-3$

King, R.G., C.I. Plosser, J.H. Stock and M.W. Watson, 1991. Stochastic trends andeconomic fluctuations. Am. Econ. Rev., 81: 819-840.

Ravn, M.O. and H. Uhlig, 1997. On adjusting the HPfilter for the frequency of observations. University of Southampton.

Shapiro, M.D. and M.W. Watson, 1988. Sources of Business Cycle fluctuations. Cambridge, MA.

Slevin,G., 2001. Potential output and the output gap in Ireland. Central Bank of Ireland.

Tommaso, P., M. Alberto and W. Thomas, 2002. Estimating Potential Output and the output gap for the Euro Area: A model based Production Function Approach. European University Institute, Florence.

Wedekind, C. and M. Milinski, 2000. Cooperation through image scoring in humans. Science, 288: 850-852. DOI: $10.1126 /$ science. 288.5467 .850

Willems, T., 2010. Visualizing the Invisible: Estimating the New Keynesian Output Gap via a Bayesian Approach. University of Oxford. 
Khavari, S.D. and S.H. Mirjalili / American Journal of Economics and Business Administration 4 (3): 180-189, 2012 